\title{
Prevalence of fibroids: a study in a semiurban area in Telangana, India
}

\author{
Juvvadi Srilatha*, Verabelly Malathi
}

Department of Obstetrics and Gynecology, Mallareddy Institute of Medical Sciences, Hyderabad, Telangana, India

Received: 14 October 2017

Accepted: 16 October 2017

\section{*Correspondence:}

Dr. Verabelly Malathi,

E-mail: malathi1174@gmail.com

Copyright: ( $)$ the author(s), publisher and licensee Medip Academy. This is an open-access article distributed under the terms of the Creative Commons Attribution Non-Commercial License, which permits unrestricted non-commercial use, distribution, and reproduction in any medium, provided the original work is properly cited.

\begin{abstract}
Background: Uterine fibroids, also known as Leiomyoma, are the most common benign neoplasm in the female genital tract and originate from the myometrium's smooth muscle. Although the uterine fibroids are diagnosed frequently, the prevalence of it in the local populations is unknown. Therefore, this study was done to observe the prevalence of the fibroids in our geographic area.

Methods: 4487 women aged between 18-50 years who came to our gynec OPD out of which 522 were positive for the presence of fibroids, were included into the study. Ultrasound examination was done for all the patients. During this examination, the uterine dimensions and the structure were assessed. The number of the fibroids were counted and noted. Biopsy sample was taken from the fibroids and sent to pathology lab for further histological examination.

Results: Out of the 4487 patients included into the study, $11.6 \%$ had fibroids. The predominant age group which was positive the presence of fiberoids was 40-59 years. 59.8\% of them were married while $40.2 \%$ were either unmarried or divorced or widowed. The body mass index for most of them was within the normal range $(60.3 \%)$, while some were slightly overweight. The most common cause of the patients to seek medical advice was menstrual disorder $(37.7 \%)$ which included heavy, irregular or no periods.

Conclusions: Fibroids was significantly associated with age, married marital status, overweight, pregnancy, menopause, childbirth and the presence of menorrhagia. Early detection would help in early management and thereby reduce the morbidity.
\end{abstract}

Keywords: Fibroids, Ultrasound, Women

\section{INTRODUCTION}

Uterine fibroids, also known as Leiomyoma, are the most common benign neoplasm in the female genital tract and originate from the myometrium's smooth muscle. ${ }^{1,2}$ The cause of the fibroids is unknown, but however, it is estimated to be caused by estrogens and progestrones which proliferate tumor growth. ${ }^{3,4}$

Fibroids are seen to rarely occur before menarche and reduce after menopause. The may be single or multiple and have a negative impact on the reproductive system, and are capable of causing severe morbidity among the women with deterioration of quality of life..$^{5}$ It is known that $20 \%-50 \%$ of women in this age group suffer from this disease. 5.4 to $77 \%$ of women have myomas, depending on the study population and races of the population. ${ }^{6}$ It is seen that in USA, the prevalence of the uterine fibroids was $60 \%$ at the age of 35, which increased to more than $80 \%$ by the age of 50 years among the African American women. However, the incidence ws observed to be lesser in Caucasian women, where the incidence was $40 \%$ by age 35 , and almost $70 \%$ by age $50 .^{7}$ The data was similar in Italy, while the incidence was lower among the Swedish women. 8,9

Risk factors for developing fibroids, such as: age, early age at menarche, reduced fertility, frequent alcohol and 
caffeine consumption, obesity, consumption of red meat, hypertension, diabetes mellitus, previous pelvic inflammatory disease and genetics have been observed.

The uterine myomas are classified into three categories according to their anatomical location: Submucous fibroids, located below the endometrium (occasionally, they develop pedicles or even completely occupy the uterine cavity); Interstitial / Intramural fibroids, located within the uterine wall; Subserous fibroids, located in the serosal surface of the uterus.

Although the uterine fibroids are diagnosed frequently, the prevalence of it in the local populations is unknown. Therefore, this study was done to observe the prevalence of the fibroids in our geographic area.

\section{METHODS}

This study was conducted by the department of OBGY at Mallareddy institute of medical sciences from July 2015 to august 2017. 4487 women who came to our Gynec OPD were included into the study. Those who were pregnant were excluded from the study.

Demographic details of all the patients such as the age of the patient at the moment of consultation, weight, height, age of menarche, number of pregnancies, pregnancy outcome deliveries, marital status, level of education, menstrual cycle and contraceptive method used, were taken from all the patients.

Ultrasound examination was done for all the patients. During this examination, the uterine dimensions and shape of the fibroid was assessed. The number of the fibroids were counted and noted. The size of the fibroids was also noted and the largest of the fibroid was identified. Specimens were sent to pathology lab for further histopathological examination after surgery.

\section{RESULTS}

Out of the 4487 patients included into the study, $522 \mathrm{had}$ fibroids (11.6\%) (Figure 1).

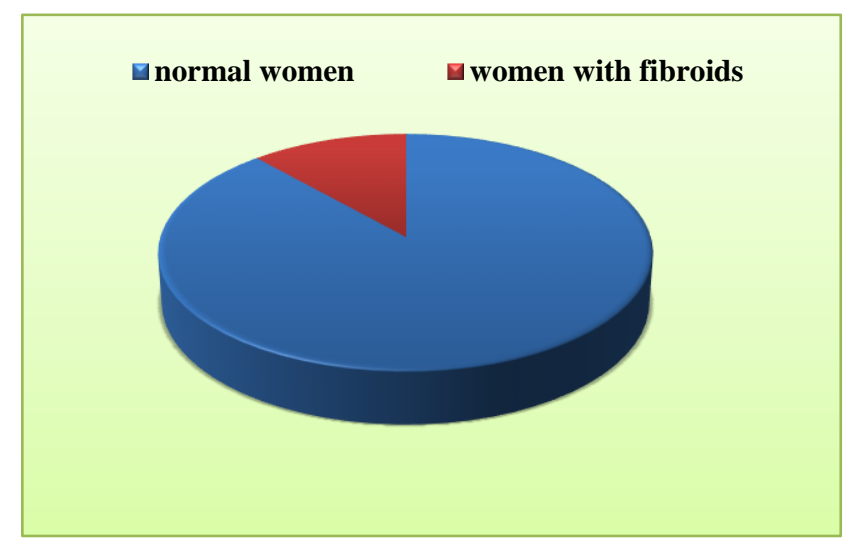

Figure 1: Prevalence of fibroids.
The predominant age group which was positive the presence of fibroids was 40-59 years (57.3\%), followed by 20-39 years $(37.2 \%)$. Most of these women were illiterate and had not had any formal education (61.9\%). Only about $10 \%$ of the women were educated above the high school level out of whoe many had discontinued. $59.8 \%$ of them were married while $40.2 \%$ were either unmarried or divorced or widowed. The body mass index for most of them were within the normal range (60.3\%), while some were slightly overweight (Table 1).

Table 1: Demographic details of the patients.

\begin{tabular}{|ll|}
\hline Variable & Number $(\%)$ \\
\hline Age & $3(0.6 \%)$ \\
\hline$<19$ & $194(37.2 \%)$ \\
\hline $20-39$ & $299(57.3 \%)$ \\
\hline $40-59$ & $26(5 \%)$ \\
\hline$\geq 60$ & \\
\hline Education & $323(61.9 \%)$ \\
\hline Illiterate & $146(28 \%)$ \\
\hline Upto high school & $53(10.1 \%)$ \\
\hline Above high school & \\
\hline Marital status & $312(59.8 \%)$ \\
\hline Married & $210(40.2 \%)$ \\
\hline Single/ divorced/ widowed & \\
\hline Body mass index & $5(1 \%)$ \\
\hline$<18.4$ & $315(60.3 \%)$ \\
\hline $18.5-24.9$ & $182(34.9 \%)$ \\
\hline $25-29.9$ & $11(2.1 \%)$ \\
\hline $30-34.9$ & $9(1.7 \%)$ \\
\hline$\geq 35$ & \\
\hline
\end{tabular}

The mean age for attaining menarche for the patients was $12.4 \pm 3.6$ and attainment of menopause was $44.6 \pm 4.1$. Most of the patients had more than 1 child. $5.7 \%$ of the patients had miscarriages in their pregnancies. Most of the patients had an intrauterine device inserted, most commonly, it was copper $\mathrm{T}$ (Table 2).

Table 2: Gynaecological history.

\begin{tabular}{|l|l|}
\hline Variable & Number \\
\hline Mean age & $12.4 \pm 3.6$ \\
\hline At menarche & $44.6 \pm 4.1$ \\
\hline At menopause & \\
\hline Pregnancies & $26(5 \%)$ \\
\hline 0 & $154(29.5 \%)$ \\
\hline 1 & $342(65.5 \%)$ \\
\hline Multiple & \\
\hline Number of deliveries & $21(4.1 \%)$ \\
\hline 0 & $161(30.8 \%)$ \\
\hline 1 & $340(65.1 \%)$ \\
\hline$\geq 2$ & $30(5.7 \%)$ \\
\hline Miscarriage & \\
\hline Contraceptives & 89 \\
\hline Pills & 139 \\
\hline IUD & 294 \\
\hline others & \\
\hline
\end{tabular}


The most common cause of the patients to seek medical advice was menstrual disorder $(37.7 \%)$ which included heavy, irregular or no periods. This was followed by pelvic symptoms such as pain $(24.1 \%)$. Infertility was observed in $23.9 \%$ of the cases (Figure 2).

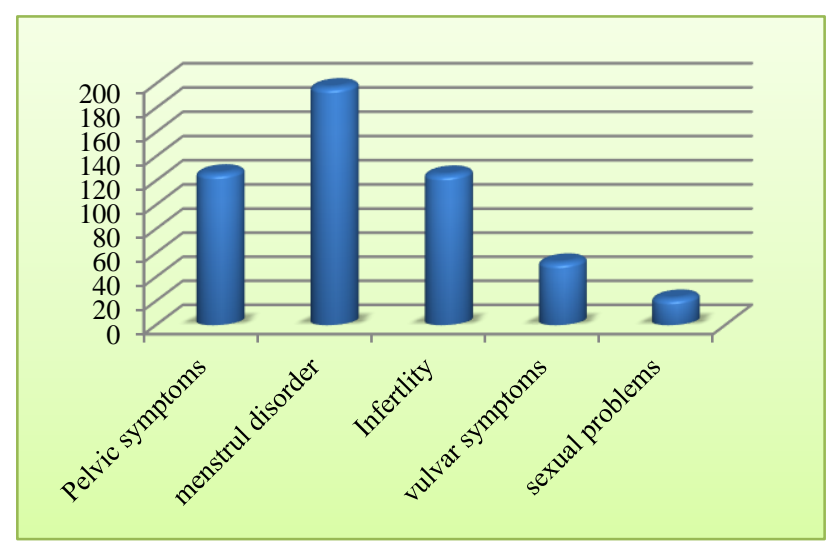

Figure 2: Complaints for seeking medical advice.

\section{DISCUSSION}

In the present study, the prevalence of fibroids among the population of our area was $11.6 \%$. In a study by Butran et al, a prevalence of $20-25 \%$ of females developing fibroids was observed. ${ }^{10}$ This was in accordance with a similar study b Marino et al, where un a prevalence of $21.4 \%$ was seen. ${ }^{11}$ In some studies very low prevalence of around 5\% was seen, while prevalence of $77 \%$ was observed by Cramer et al. ${ }^{9,12}$

In our study, we found an increase in the incidence in fibroids in the 40-59 years age group. A similar result was observed in another study by Chen et al wherein the presence of this condition was more frequently seen in the 40-44 years age group. ${ }^{13}$ The women affected with fibroids in our study were predominantly married. However, this situation was not found to be significant. This was in accordance to another study by Olantiwo et al who also fund no association between the incidence of fibroids and the marital status of the patient. ${ }^{14}$ However, a correlation of the marital status and the incidence of fibroids were observed in a study by Choi et al. ${ }^{15}$ However, the incidence of fibroids was found to be higher among the single women in a study by Novak et al. $^{16}$

A higher BMI, in present study showed a higher prevalence of the condition, which was in concordance to a study by Shikor et al. ${ }^{17}$ However, no significance between the wo conditionswas reported by Samadi et al and Parazzini et al. ${ }^{18,19}$

Post menopausal women in current study have shown a higher incidence of fibroids as compared to the premenopausal women, which was statistically significant. However, no significance was found in a study by Cramer et al, who has also reported smaller sized fibroids compared to the present study.

The prevalence of firoids was found to be lesser In women who were on contraceptive pills rather than those who used IUDs or other contraceptive measures. These results were consistent with those of Chiaffarino et al, who found only $30 \%$ of women on oral pills with fibroids. ${ }^{20}$ However, a study by Wise et al reported otherwise. $^{21}$

\section{CONCLUSION}

The prevalence of fibroids in women in our area was comparatively lesser than the rest of the world. However, it was significantly associated with age, marital status, obesity, pregnancy, menopause, childbirth and the presence of menorrhagia. Early detection would help in early management and thereby reduce the morbidity.

\section{Funding: No funding sources}

Conflict of interest: None declared

Ethical approval: The study was approved by the Institutional Ethics Committee

\section{REFERENCES}

1. Parker WH. Etiology, symptomatology, and diagnosis of uterine myomas. Fertil Steril. 2007;87(4):725-36.

2. Kempson RL, Hendrickson MR. Smooth muscle, endometrial stromal, and mixed Müllerian tumors of the uterus. Mod Pathol. 2000;13(3):328-342.

3. Rein MS, Barbieri RL, Friedman AJ. Progesterone: a critical role in the pathogenesis of uterine myomas. Am J Obstet Gynecol. 1995;172(1 Pt 1):14-18.

4. Andersen J. Growth factors and cytokines in uterine leiomyomas. Semin Reprod Endocrinol. 1996;14(3):269-82.

5. Sparic R. Uterine myomas in pregnancy, childbirth and the puerperium. Srp Arh Celok Lek. 2014;142(12):118-24.

6. Downes E, Sikirica V, Gilabert-Estelles J, Bolge SC, Dodd SL, Maroulis C, et al. The burden of uterine fibroids in five European countries. Eur J Obstet Gynecol Reprod Biol. 2010;152(1):96-102.

7. Laughlin SK, Baird DD, Savitz DA, Herring AH, Hartmann KE. Prevalence of uterine leiomyomas in the first trimester of pregnancy: an ultrasoundscreening study. Obstet Gynecol. 2009;113(3):630-5.

8. Eskenazi B, Warner M, Samuels S, Young J, Gerthoux PM, Needham L, et al. Serum dioxin concentrations and risk of uterine leiomyoma in the Seveso Women's Health Study. Am J Epidemiol. 2007;166(1):79-87.

9. Borgfeldt C, Andolf E. Transvaginal ultrasonographic findings in the uterus and the endometrium: low prevalence of leiomyoma in a random sample of women age 25-40 years. Acta 
Obstetricia et Gynecologica Scandinavica. 2000;79(3):202-7.

10. Buttram VC, Reiter RC. Uterine leiomyomata: etiology, symptomatology, and management. Fertil Steril. 1981;36(4):433-45. Marino JL, Eskenazi B,

11. Marino JL, Eskenazi B, Warner M, Samuels S, Vercellini P, Gavoni N, Olive D. Uterine leiomyoma and menstrual cycle characteristics in a populationbased cohort study. Human Reprod. 2004 Oct 1;19(10):2350-5.

12. Cramer SF, Patel A. The frequency of uterine leiomyomas. Am J Clin Pathol. 1990;94(4):435-8.

13. Chen CR, Buck GM, Courey NG, Perez KM, Wactawski-Wende J. Risk factors for uterine fibroids among women undergoing tubal sterilization. Am J Epidemiol. 2001;153(1):20-6.

14. Olatinwo AW, Ofiong R. An Analysis of Surgically Treated Cases of Uterine Fibroids at the University of Ilorin Teaching Hospital, Ilorin, Nigeria. Nigerian J Surg Res. 2000;2(1):6-11.

15. Choi JH, Kim JK. Influences of health-related factors on uterine myoma. J Korea Contents Assoc. 2010;10(1):325-33.

16. Novak ER WJ. Myoma and other benign tumors of the uterus. Gynecologic and Obstetric Pathology. 8 th ed ed. Philadelphia, USA: W.B. Saunders; 1979:260-78.
17. Shikora SA, Niloff JM, Bistrian BR, Forse RA, Blackburn GL. Relationship between obesity and uterine leiomyomata. Nutrition. 1991;7(4):251-5.

18. Samadi AR, Lee NC, Flanders WD, Boring JR, 3rd, Parris EB. Risk factors for selfreported uterine fibroids: a case-control study. Am J Public Health. 1996;86(6):858-62.

19. Parazzini F, La Vecchia C, Negri E, Cecchetti G, Fedele L. Epidemiologic characteristics of women with uterine fibroids: a case-control study. Obstet Gynecol. 1988;72(6):853-7.

20. Chiaffarino F, Parazzini F, La Vecchia C, Marsico S, Surace M, Ricci E. Use of oral contraceptives and uterine fibroids: results from a case-control study. $\mathrm{Br}$ J Obstet Gynecol. 1999;106(8):857-60.

21. Wise LA, Palmer JR, Harlow BL, Spiegelman D, Stewart EA, Adams-Campbell LL et al. Reproductive factors, hormonal contraception, and risk of uterine leiomyomata in AfricanAmerican women: a prospective study. Am J Epidemiol. 2004;159(2):113-23.

Cite this article as: Srilatha J, Malathi V. Prevalence of fibroids: a study in a semiurban area in Telangana, India. Int J Reprod Contracept Obstet Gynecol 2017;6:5247-50. 